\title{
COMPLICACIONES EN EL USO DEL HIPOCLORITO DE SODIO DURANTE EL TRATAMIENTO ENDODÓNTICO: UNA REVISIÓN
}

\author{
Humberto Ferreira Arquez \\ Odontólogo, U. de Cartagena, Especialista en Endodoncia, U. Santo Tomás, \\ Docente de la Facultad de Medicina, U. de Pamplona.
}

Dirección de correo electrónico: humfear@unipamplona.edu.co

\begin{abstract}
RESUMEN
La irrigación del conducto radicular juega un papel importante en el debridamiento y desinfección del sistema de conductos, y es una parte integral de los procedimientos de preparación biomecánica. La contaminación bacteriana del conducto radicular es la mayor preocupación en endodoncia; la eliminación de microorganismos y tejido necrótico del conducto radicular es esencial para garantizar el resultado exitoso del tratamiento. Indiferente de la técnica utilizada, particular atención debe ser tenida en cuenta para un apropiado y seguro uso de esta solución química. El objetivo de este artículo es revisar la literatura concerniente a la etiología, la sintomatología y las posibles complicaciones durante la irrigación de conducto radicular. [Ferreira $\mathrm{H}$. Complicaciones en el uso del hipoclorito de sodio durante el tratamiento endodóntico: una revisión. Revista Ustasalud Odontología 2007; 6: 45 - 52]
\end{abstract}

Palabras clave: Hipoclorito de sodio, Efectos tóxicos, Complicaciones durante la irrigación.

\section{COMPLICATION IN THE USE SODIUM HYPOCHLORITE DURING ENDODONTIC TREATMENT: A REVIEW.}

\begin{abstract}
Root canal irrigation plays an important role in the debridement and disinfection of the canal systems, and is an integral part of the biomechanical preparation procedures. The bacterial contamination of the root canal is of great concern in endodontics; the elimination of microoganisms and necrotic tissues from the root canal is essential for a successfully outcome. Regardless of the technique used, particular attention must be given to the appropriate and safe use of the chemical solution. The literature concerning the aetiology, symptomatology and complications during root canal irrigation is reviewed.
\end{abstract}

Key words: Sodium hypochlorite, Toxic effect, Complications during irrigation.

Recibido para publicación: 29 de enero de 2007. Aceptado para publicación: 9 de julio de 2007.

\section{INTRODUCCIÓN}

La lejía es un compuesto químico llamado hipoclorito de sodio, disuelto en agua. Fue desarrollado por el francés Berthollet en 1787 para blanquear telas. Luego, a fines del siglo XIX, Luis Pasteur comprobó su incomparable poder de desinfección, su uso se extendió a la defensa de la salud contra gérmenes y bacterias.

La lejía o simplemente cloro como también se le conoce, se produce industrialmente al mezclar agua con sal, filtrándola y pasándola por un proceso de electrólisis que descompone el agua en cloro, hidróxido de sodio e hidrógeno. Luego se combinan el cloro, el hidróxido de sodio y agua produciéndose el hipoclorito de sodio o lejía, que se envasa para su distribución donde su concentración más comúnmente encontrada es al 5\%. Es una solución muy alcalina (pH: 12). La solución es muy hipertónica ( $2800 \mathrm{mOsmol} / \mathrm{Kg}){ }^{1}$

Está demostrado que el NaOCL es un agente químico efectivo contra una amplia variedad de bacterias y se le reconoce su habilidad para la disolución de tejido sea vital o necrótico. ${ }^{2-7}$ Sin embargo, también ha sido demostrado su efecto tóxico sobre el tejido vital entre éstas se encuentran la hemólisis, ulceración de la piel, necrosis; igualmente puede causar irritación a los tejidos periapical y periodontal. ${ }^{1,8-11}$

Se encuentran descritos en la literatura una serie de incidentes relacionados con el manejo del hipoclorito de sodio durante la terapia endodóntica.

\section{Daño a la ropa:}

Esta podría considerarse una de las más comunes por la condición que posee el NaOCL de sustancia 
blanqueadora. Por tal motivo, debe tenerse la precaución de verificar una buena adaptación de la aguja con la jeringa. Tener el cuidado de revisar que dentro de la jeringa no queden burbujas o espacios de aire, lo cual hace que ocurra goteo a través de la punta de la aguja.

Cargar la jeringa con la solución lejos del paciente y de la bandeja porta instrumental de la unidad odontológica, colocarle al paciente las barreras suficientes y adecuadas. Verificar que la aguja no esté tapada pues esto hace que el operador imprima fuerza sobre el émbolo de la jeringa lo cual puede desalojar a la aguja de la jeringa y esparcir con presión su contenido hacia el operador, el paciente y la auxiliar. ${ }^{12}$ No retirar la jeringa antes de 3 o 4 segundos después de haber suspendido la presión, pues por ser el diámetro de ésta mucho mayor que el de la aguja, puede continuar saliendo el líquido.

\section{Contacto del NaOCl con los ojos:}

El contacto de esta sustancia con los ojos se traduce en dolor, eritema de la córnea, sensación de quemazón, fotofobia, blefaroespasmo. Pueden presentarse reacciones de leves a severas dependiente de la cantidad, concentración y tiempo de contacto de la solución (erosión del epitelio corneal, pérdida de células epiteliales de la córnea, necrosis isquémica de la esclerótica y conjuntiva ocular, borramiento del contorno de la línea externa pupilar, blanqueamiento de la esclerótica y conjuntiva). Por tanto, se debe actuar con rapidez y lavar profusamente el ojo, preferiblemente con solución salina estéril, o agua de la llave si no se dispone de la solución salina, por períodos de 10 a 15 minutos y remitir inmediatamente al paciente a consulta con oftalmólogo o médico general. ${ }^{13}$

Se debe evitar este tipo de situaciones, tomar en cuenta las consideraciones, hechas anteriormente, en cuanto al manejo cuando se carga y transporta la jeringa con la solución, especial cuidado debe tenerse con los sistemas de ultrasonido coadyuvante de la irrigación por el hecho que ocasionan aspersión o aerosol de esta sustancia por fuera del campo operatorio que pueden ser inhaladas por el paciente y causar irritación del tracto respiratorio, laringe, tráquea y provocar estornudos.

\section{Contacto con la piel:}

Serper y colaboradores reportaron un caso de quemadura de piel alrededor de la boca del paciente por filtración del NaOCL a través de la tela de caucho, el paciente manifestó la molestia al operador, pero no fue atendida. ${ }^{14} \mathrm{El}$ tratamiento médico fue tópico con crema (hammamelis virginiana extract- hamelin) aplicada tópicamente 2 veces al día por 2 semanas, durante este tiempo el paciente tuvo una sensación de quemazón en la zona por 3 días, el tejido de cicatrización (costra) se desprendió a los 7 días, la sensibilidad en la zona continuó por 10 días y la decoloración causada por la quemadura desapareció a los 3 meses.

Nota: en el mercado farmacéutico nacional se encuentra el hammamelis virginiana al 10\%, junto con otros componentes adicionales, bajo el nombre comercial de Eucerin ${ }^{\circledR}$ del Laboratorio BDFBeiersdorf.

\section{Ingestión de hipoclorito de sodio:}

Por una mala adaptación de la tela de caucho y la no utilización de un adecuado método de succión, puede haber filtración del $\mathrm{NaOCl}$ dentro de la cavidad oral. Debe prestarse especial atención, generalmente la molestia que causa en el paciente el contacto de la solución con la cavidad oral, la sensación de quemazón y el sabor desagradable de la solución, son manifestados y en ningún caso debe omitirse.

Cualquier solución con un $\mathrm{pH}$ alcalino tiene la potencialidad de causar una lesión tisular si es ingerido. La extensión de la lesión no depende únicamente del $\mathrm{pH}$ sino también del volumen ingerido, tiempo de contacto, viscosidad y concentración.

Los síntomas y signos asociados con una lesión tisular por álcalis incluyen dolor de la boca, odinofagia, sialorrea, disfagia, vómito,dolor abdominal y hematemesis. Si hay compromiso de la laringe, el edema local puede causar alteración respiratoria, estridor y disfonía.

La lesión tisular extensa se puede asociar con fiebre, taquicardia, hipotensión y taquipnea. La evaluación de la orofaringe puede mostrar áreas quemadas de la mucosa, la cual se ve blanca o con parches grises con bordes eritematosos. La ausencia de quemaduras visibles en los labios, boca o garganta no implica necesariamente la ausencia de quemaduras significativas en el esófago.

Las quemaduras severas por la ingestión de álcalis pueden conducir a complicaciones que amenacen la vida como perforación esofágica y mediastinitis. ${ }^{15}$ Debe remitirse al paciente para valoración con médico general y la necesidad o no de valoración por gastroenterólogo.

\section{Reacciones alérgicas:}

Aunque existen pocos reportes en la literatura dental sobre reacciones alérgicas al $\mathrm{NaOCl},{ }^{16-18}$ si se ha establecido en la literatura médica la existencia de reacciones alérgicas a esta sustancia. ${ }^{19}$ Uno de los 
puntos más importantes antes de realizar cualquier procedimiento clínico incluida la endodoncia es la realización de una historia clínica meticulosa e incluir en el interrogatorio del paciente un listado de preguntas concernientes a antecedentes de alergias a las sustancias y/o componentes de los materiales que se van utilizar durante el procedimiento; si hay alguna sospecha acerca de alergias a productos de limpieza, debe referirse al paciente para realizarse pruebas especializadas de hipersensibilidad

Caliskan y colaboradores refieren que en los pacientes hipersensibles al hipoclorito, ${ }^{17}$ además del dolor severo, sensación de ardor, inflamación, equimosis y hemorragia a través del conducto; se observa dificultad para respirar, hipotensión y eritema, por lo cual debe recibir atención médica de inmediato, en un servicio de salud. En estos casos se recomienda irrigar el sistema de conductos radiculares alternando peróxido de hidrógeno y solución fisiológica.

Una alternativa en la irrigación es la utilización de compuestos a base de gluconato de clorhexidina al $2 \%$, doxiciclina al $0.01 \%$ o $0.005 \%$. $^{20,21}$

\section{Inyección accidental de hipoclorito de sodio dentro de los tejidos blandos:}

Algunos operadores utilizan los cárpules vacíos de anestesia para cargarlos con hipoclorito de sodio y utilizarlos para la irrigación de conductos; la falta de previsión, de un adecuado almacenamiento y la no señalización de este tipo de sustancias, puede generar el hecho de inadvertidamente realizar un bloqueo nervioso con hipoclorito de sodio. ${ }^{22,23} \mathrm{Se}$ debe enfatizar en el hecho que nunca debe practicarse este tipo de maniobras de envasar $\mathrm{NaOCl}$ en cárpules de anestesia.

Un caso de inyección de aproximadamente 0.1 a $0.2 \mathrm{ml}$ de $\mathrm{NaOCl}$ a una concentración de $2.5 \%$ en la mucosa palatina, ${ }^{23}$ el paciente reportó repentino y severo dolor durante 2 días; el examen de la zona mostró una zona necrótica de 1 a $2 \mathrm{~mm}$ de diámetro que en su centro tenía una coloración blanca amarillenta y en sus bordes una tumefacción y un halo de color violeta, dolorosa a la palpación. No hubo evidencia radiográfica de lesión ósea. Hubo cicatrización después de 15 días sin complicaciones. Se realizó un manejo conservativo de la zona donde se logró la cicatrización sin necesidad de efectuar procedimiento alguno.

En el caso reportado de un bloqueo nervioso mandibular con $1.8 \mathrm{ml}$ de $\mathrm{NaOCl}$ al $5.25 \%,{ }^{22}$ el paciente manifiesta severo dolor, edema del espacio pterigomandibular, faríngeo y peritonsilar del lado inyectado, trismus. El paciente fue hospitalizado y conducido a la unidad de cuidados intensivos por la posible obstrucción de la vía aérea, 5 horas después de admitido la tumefacción no se incrementó ni se extendió, fue localizada en la zona peritonsilar, borde posterior de la mandíbula, área cigomática y borde anterior del músculo masetero, 4 días después hubo resolución del caso. El manejo médico consistió en administración intravenosa de dextrosa al 5\%, fentanyl al $0.05 \mathrm{mg}$ y demerol de $50 \mathrm{mg}$ intravenoso para el manejo del dolor, eritromicina $250 \mathrm{mg}$ cada 6 horas- vía oral, dieta blanda por la dificultad del paciente para deglutir.

\section{Extrusión de $\mathrm{NaOCl}$ hacia los tejidos periapi- cales:}

Durante la preparación y limpieza de los conductos, es importante la eliminación de las bacterias y sus toxinas para garantizar la viabilidad a corto, mediano y largo plazo del tratamiento y asegurar el no desarrollo de lesiones periapicales. ${ }^{24,25} \mathrm{Si}$ se tiene en cuenta el tamaño y forma de los instrumentos endodónticos es lógico asumir que la instrumentación por sí sola es insuficiente para lograr una apropiada limpieza; bacterias, tejido residual, detritus de dentina contaminados pueden persistir en las irregularidades del sistema de conductos. ${ }^{26,27}$ Por tanto, la preparación endodóntica debe ser acompañada de soluciones irrigantes con capacidad de disolver tejido orgánico, desinfectar el sistema de conductos, proveer una lubricación del conducto durante la preparación biomecánica, eliminar los detritus de dentina contaminados; uno de los más conocidos irritantes utilizados y estudiados es el hipoclorito de sodio debido a sus propiedades físico-químicas y antibacteriales; sin embargo, el $\mathrm{NaOCl}$ puede irritar el tejido periodontal y periapical; en altas concentraciones pueden ser observados cambios necróticos y muerte de fibroblastos. $3,6,9,11,20,24,28,29$

Los accidentes durante la irrigación del sistema de conductos relacionados con la extrusión hacia los tejidos periapicales están relacionados con factores tales como:

- Perforaciones radiculares no detectadas.

- Fracturas radiculares no detectadas

- Resorción radicular

- Foramen apical amplio

- Destrucción de la constricción apical por sobrepreparación..$^{30}$

- Excesiva presión por parte del operador en el émbolo de la jeringa de irrigación.

- Utilización de agujas convencionales, con extremo en bisel.

- Perdida de la longitud radicular. 
- Profundizar y llevar la punta de la aguja a un punto dentro de la raíz dentaria en el cual quede ajustada-prensada contra las paredes.

La severidad de las reacciones descritas en la literatura va desde moderadas a severas y desde inmediatas a tardías. El grado de destrucción cuando el hipoclorito entra en contacto con los tejidos sanos es determinado por la duración del contacto y concentración del $\mathrm{NaOCl},{ }^{31}$ un factor sobre el cual no tenemos predicción del tipo y gravedad de la reacción son los factores relacionados con el huésped.

El mecanismo de respuesta de los tejidos puede ser similar al propuesto en el desarrollo del edema angioneurótico, donde hay liberación de histamina o sustancias parecidas a la histamina que producen vasodilatación, con un transexudado de plasma y abundante hemorragia. ${ }^{32}$

\section{Extrusión del hipoclorito dentro del seno maxilar:}

Anatómicamente las raíces de los molares maxilares se encuentran en un gran porcentaje de los casos en íntima relación con el piso del seno maxilar, separados por una delgada lámina ósea. ${ }^{33}$

Ehrich y colaboradores reportaron que durante la irrigación con hipoclorito de sodio al 5.25\% de la raíz palatina del primer molar superior derecho, ${ }^{34}$ el paciente experimentó el sabor del hipoclorito en su garganta y hubo salida de un líquido claro por la fosa nasal derecha, se realizó lavado y aspiración en la faringe; el paciente reportó además congestión nasal y una leve sensación de quemazón en el seno maxilar derecho, no se evidenció hemorragia a través de la raíz palatina, ni tumefacción extra o intraoral.

El tratamiento por parte del operador consistió en irrigar a través del conducto palatino con $30 \mathrm{ml}$ de solución salina, dentro de los 5 minutos después de la exposición, que fluyó dentro del seno maxilar, la cavidad nasal y faringe. El paciente fue medicado con amoxicilina $500 \mathrm{mg}$ cada 8 horas por 7 días e ibuprofeno de $800 \mathrm{mg}$ cada 6 horas. Al primer día de valoración posterior al incidente el paciente reportó leve inflamación y congestión del seno maxilar derecho y salida de material de color marrón al sonarse la nariz, citas sucesivas hasta 4 días después, el paciente estuvo asintomático.

Kavanagh y Taylor reportaron un caso de extrusión de $\mathrm{NaOCl}$ dentro del seno maxilar durante el tratamiento del diente segundo premolar superior derecho, ${ }^{35}$ el paciente experimentó dolor facial agudo y tumefacción, los intentos por lograr el drenaje del seno a través de la cavidad dental de acceso fue- ron infructuosos y hubo necesidad de realizar drenaje quirúrgico, (Caldwell-Luc) bajo anestesia general. A pesar de la resolución del cuadro clínico inicial (sinusitis aguda química), el diente 15 permaneció doloroso y fue extraído tres meses después.

\section{Extrusión del hipoclorito de sodio dentro de los tejidos periapicales:}

Se han descrito las reacciones a este incidente: $:^{1,22,31,32,35-37}$

- Severa e inmediata reacción inflamatoria

- Dolor severo.

- Edema y profusa hemorragia intersticial.

- Profusa hemorragia a través del diente.

- Incremento del edema y equimosis en el transcurso de las horas o días que puede ser uni o bilateral.

- Infección secundaria.

- Necrosis del tejido.

- Parestesia.

- Obstrucción de la vía aérea.

- Obstrucción de la vía alimenticia.

- Trismos.

- Parestesia.

- Pérdida de la sensibilidad de la zona afectada y circunvecinas.

Becking presentó tres casos de inadvertida inyección de $\mathrm{NaOCl}$ dentro de los tejidos periapicales; ${ }^{37}$ en el primer caso, durante el tratamiento del diente 37, con una concentración desconocida del $\mathrm{NaO}$ $\mathrm{Cl}$, el paciente experimentó una progresiva tumefacción del lado izquierdo de la mandíbula que se extendió hasta el cuello; a los 7 días fue evidente necrosis de la mucosa y parestesia; 5 días después de tratamiento con antibióticos y analgésicos la tumefacción disminuyó, la parestesia se resolvió a los 10 días y la cicatrización de la mucosa a los 2 meses. En el segundo caso, durante el tratamiento del diente 27, se extruyó $\mathrm{NaOCl}$ de concentración desconocida, que causó tumefacción periorbitaria, dolor severo en la mejilla, ojo y región temporal del lado afectado, el paciente fue medicado solamente con analgésicos y al cabo de 2 semanas hubo recuperación. En el tercer caso durante el tratamiento endodóntico del diente 35 , la extrusión de $\mathrm{NaO}$ $\mathrm{Cl}$ produjo dolor severo, tumefacción y anestesia del nervio mentoniano; no se suministró terapia antibiótica, 4 días después se evidenció necrosis e infección, y se inició la terapia antibiótica, la resolución del proceso (dolor y tumefacción) tomó un mes; la anestesia de la zona cambió gradualmente a un estado de hiperestesia. 
Becker y colaboradores reportaron que durante el tratamiento endodóntico del diente $14 ;^{31} 0,5 \mathrm{cc}$ de $\mathrm{NaOCl}$ al 5,25 \% fue extruído a los tejidos periapicales, la paciente experimentó una fuerte reacción a los 30 segundos, manifestada en edema de labio y mejilla del lado afectado que se extendió a la zona orbitaria , equimosis en la zona cigomática; abundante hemorragia a través del conducto que cesó a los 6 minutos (después de una continua aspiración), hubo dolor severo irradiado hacia la nariz, la zona parotidea, oído, en la zona mandibular (gonion), y en la región nasopalpebral; se aplicaron compresas calientes y frías en la zona afectada y se instauró terapia analgésica y antibiótica, y se dieron instrucciones de continuar con la aplicación de compresas frías; la tumefacción aumentó en el transcurso de pocas horas e incluso involucró parcialmente la zona orbitaria izquierda pero con disminución del dolor; para incrementar la dilatación capilar superficial y acelerar la circulación sistémica local se le indicó a la paciente cambiar las compresas frías por calientes; un mes después hubo resolución completa del cuadro clínico y se terminó el tratamiento de conductos.

Reeh y Messer reportaron la extrusión inadvertida de 1 a $2 \mathrm{ml}$ de $\mathrm{NaOCl}$ al $1 \%$ a través de una perforación radicular del diente $11,{ }^{36}$ no detectada en el examen- diagnóstico inicial, la paciente experimentó inmediatamente extremo dolor a nivel de la zona nasal y premolar, el cual se disipó al cabo de un tiempo y el operador continuó con el tratamiento; se presentó drenaje (no especificado el tipo) excesivo a través del diente, el cual fue dejado abierto, se prescribieron analgésicos y se citó a la paciente para el día siguiente. Al otro día, la paciente fue valorada en el servicio de urgencias, presentaba tumefacción y eritema en el lado derecho de la cara que se extendía a la zona infraorbitaria, tumefacción del área perinasal y ausencia de sensibilidad a la palpación en esta área y en el labio superior, presencia de un área ulcerativa en la mucosa por encima del incisivo central, hubo resolución del cuadro clínico de la tumefacción a los 15 días; pero la paciente persistió con la sensación de parestesia y hormigueo en el labio superior y nariz del lado afectado aún después de 15 meses de evolución.

Sabala y Powell, reportaron extrusión de hipoclorito de sodio al 5,25\% durante un tratamiento endodóntico del diente 25 , la paciente manifestó repentinamente dolor severo, y una rápida tumefacción que comprometía la mejilla, y área infraorbitaria; se detuvo el procedimiento, se infiltró una segunda cárpula de anestesia y se inició terapia con compresas frías en la zona afectada, se logró disminución del dolor a los 5 minutos. Se decidió terminar en la misma cita el tratamiento endodóntico y realizar procedimiento de trepanación dejando un dren de tela de caucho y se prescribió crioterapia por lapsos de 15 minutos durante las próximas 4 a 6 horas; 24 horas después la paciente presentaba diseminación de la tumefacción a la zonas submandibular y submentoniana y equimosis de la zona que se extendía por el cuello y se insinuaba hasta el área supraesternal. Fue prescrita terapia antibiótica y se presentó resolución del proceso a los 9 días. ${ }^{32}$

Gatot y colaboradores reportaron un incidente de extrusión de $\mathrm{NaOCl}$ durante un retratamiento del diente 11 , con la aparición de una repentina y rápida tumefacción de la mejilla y del labio superior; a los pocos minutos, involucraba la zona infraorbitaria y el dolor era severo. La paciente fue remitida a urgencias y se le suministraron $100 \mathrm{mg}$ de hidrocortisona intravenosa, 12 millones de Unidades de Penicilina G Sódica y se mantuvo una dosis de $200 \mathrm{mg}$ de hidrocortisona diariamente. Treinta y seis horas después la zona presentaba equimosis y apareció un área necrótica epitelial sobre el labio superior, dolor en el ojo derecho, visión borrosa e irregular, y coloración a nivel de la córnea. Se decide bajo anestesia general realizar un debridamiento quirúrgico de una gran cantidad de tejido necrótico; dos semanas después hubo cicatrización de la herida pero dejó cicatriz y un hoyuelo que indicando la pérdida de tejido subcutáneo y conectivo, adicionalmente la paciente manifestaba anestesia del nervio infraorbitario derecho. ${ }^{9}$

Mehra y colaboradores reportaron un caso donde se formó un hematoma facial posterior a la inyección inadvertida de hipoclorito de sodio en los tejidos periapicales. ${ }^{38}$ Este caso requirió la hospitalización del paciente, la administración de antibióticos vía endovenosa, la realización de múltiples incisiones quirúrgicas bajo anestesia general para facilitar la descompresión del hematoma y la colocación de un drenaje por 2 días, 5 semanas después del procedimiento hubo resolución del proceso.

La tumefacción y la equimosis comprometían el lado izquierdo de la cara incluyida la zona periorbitaria bilateral, ángulo de la mandíbula y alrededor de los labios. Bucalmente, la equimosis se extendía a la zona del vestíbulo y área retromolar, en el transcurso de las 2 horas siguientes se observó incremento del dolor, diseminación de la tumefacción al área temporal, submandibular, más compromiso de la zona periorbitaria y palpebral que impedía que la paciente pudiera abrir el ojo izquierdo, trismus, odinofagia; la equimosis se extendió a la zona de los pilares tonsilares

Borden y colaboradores reportaron un accidente de extrusión de $\mathrm{NaOCl}$ durante el tratamiento del se- 
gundo molar inferior izquierdo; ${ }^{39}$ la reacción inmediata de dolor severo hizo que el procedimiento no fuera concluido. Durante las 8 horas siguientes, la tumefacción involucró los espacios submandibular, submentoniano y sublingual bilateralmente, lo que produjo una marcada elevación de la lengua, trismus, equimosis del piso de la boca, de la lengua, del paladar y de la zona retromolar. La paciente requirió intubación nasotraqueal, se realizó drenaje quirúrgico bilateral para descomprimir la zona y se realizó la exodoncia del molar. Durante 36 horas permaneció intubada en la unidad de cuidados intensivos, fue dada de alta a las 48 horas. En un mes hubo resolución completa del proceso.

Witton y colaboradores describieron dos casos durante la terapia de conductos incisivo lateral superior derecho. ${ }^{40} \mathrm{El}$ paciente manifestó repentino dolor y tumefacción mientras era irrigado el conducto, 24 horas después la tumefacción se extendía por debajo del borde de la mandíbula y la zona orbitaria derecha; se presentó equimosis infraorbitaria, equimosis subcutánea y edema del labio superior derecho, necrosis y ulceración de la mucosa labial, trismus. Alteración en la sensibilidad nerviosa de la zona de distribución del nervio infraorbitario, compromiso de ramos del nervio facial traducidos en pérdida de la función del labio superior, mejilla y caída de la comisura bucal. Se realizó tratamiento no invasivo con Dexametasona $8 \mathrm{mg}$ cada 8 horas I.V., por dos días, antibiótico y analgésicoterapia. Un mes después había resolución del proceso, hubo disminución de la parestesia del nervio infraorbitario, aunque el compromiso del nervio facial permanecía evidente y su resolución fue seis meses después. El segundo caso, durante el tratamiento endodóntico del diente 15 y posterior a la irrigación se presentó dolor severo y tumefacción. ${ }^{41}$ Seis horas después del incidente, se presenta una marcada tumefacción en el lado derecho de la cara, pérdida de la sensibilidad en la zona que recorre el nervio infraorbitario y compromiso de la rama bucal del nervio facial, el tratamiento fue igual al expuesto en el primer caso; ${ }^{40}$ un mes después hubo recuperación progresiva del ramo bucal del nervio facial, aunque permanecía un síntoma de parestesia en el labio superior del lado derecho, la recuperación completa de la sensibilidad se dio a los tres meses.

\section{DISCUSIÓN}

Los casos revisados nos debe llamar la atención sobre la necesidad de ser siempre precavidos y tomar todas las medidas de seguridad y protección para el paciente y operador al momento de decidir realizar un tratamiento de conductos, las cuales ini- cian con una meticulosa y estricta historia clínica, firma por parte del paciente, del consentimiento informado.

El $\mathrm{NaOCl}$ es la sustancia más comúnmente utilizada y ampliamente estudiada para lograr una desinfección y debridamiento adecuado del sistema de conductos, sin embargo, las secuelas por un uso no apropiado y seguro de esta solución química puede generar complicaciones médicas al paciente y legales al profesional.

Los protocolos para prevenir los accidentes con $\mathrm{NaOCl}$ se pueden agrupar:

Historia clínica, debe incluir el ítem de antecedentes de reacciones alérgicas, incluyendo a productos de limpieza que contengan cloro; y en caso de sospecha remita a especialistas para la realización de algunas pruebas de sensibilidad

Usar siempre el dique de goma.

1. Protección adecuada para el paciente (baberos impermeables).

2. No utilizar los cárpules de anestesia vacíos para llenarlos con $\mathrm{NaOCl}$.

3. Utilizar las jeringas para irrigación fabricadas especialmente para este fin.

4. No utilizar jeringas hipodérmicas comunes.

5. Verificar, lejos del paciente que la luz y punta de la aguja estén permeables.

6. Verificar una buena adaptación de la aguja con la jeringa.

7. Verificar que no queden burbujas dentro de la jeringa pues ocasionan goteos así no se ejerza presión sobre el émbolo.

8. Cargar la jeringa con el $\mathrm{NaOCl}$, lejos del paciente.

9. Colocar la aguja de irrigación dentro del conducto sin ejercer presión.

10. Desplazar suavemente el émbolo de la jeringa

11. En caso de pulpas sangrantes o dientes que presenten ápices inmaduros, evitar la combinación de $\mathrm{NaOCl}$ con peróxido de hidrógeno a cualquier concentración; puede presentarse extrusión de hipoclorito e inclusive un enfisema por la acción del peróxido de hidrógeno. ${ }^{42}$

12. Verificar, radiográficamente, la longitud de trabajo antes de instrumentar e irrigar. La distancia de la punta de la aguja debe estar de 2 a $3 \mathrm{~mm}$ del ápice.

13. Realizar movimientos de la aguja, de adentro hacia afuera del orificio del conducto; para asegurar que la misma se encuentre libre.

14. Colocar topes de caucho en la aguja que indiquen la longitud correcta hasta la cual debe introducirla e irrigar. Verificar el posiciona- 
miento del tope de caucho entre cada sesión de irrigación durante el procedimiento

En caso de presentarse un accidente con hipoclorito de sodio por extrusión:

1. Evite el pánico, reconocer que ha ocurrido un accidente con $\mathrm{NaOCl}$ y actuar con rapidez.

2. Suspender el tratamiento de conductos.

3. Tranquilizar y explicarle al paciente la situación.

4. Control inmediato del dolor con la aplicación de un refuerzo anestésico.

5. Si se presenta, realizar el control de la hemorragia a través del diente mediante aspiración, si no logra controlarla deje abierto el diente por 24 horas.

6. Aplicar compresas frías durante las primeras 6 horas y posteriormente compresas tibias en la zona afectada.

7. No enviar al paciente a casa con una fórmula de analgésicos y antibióticos. Recuerde que la severidad de la reacción está influida por la cantidad, concentración y tiempo de contacto de la solución con los tejidos; pero un factor determinante e impredecible es el relacionado con el huésped, con la respuesta inmunitaria y liberación de mediadores químicos.

8. Llevar al paciente a un servicio de urgencias, solicitar la interconsulta de un especialista sea endodoncista, cirujano oral o cirujano maxilofacial.

9. Inicialmente, el manejo debe ser intravenoso con corticoides, penicilina a concentraciones y dosis adecuadas dependientes del peso, analgésicos fuertes del tipo opioides (debe existir un buen control del dolor), monitoreo durante las primeras horas (desde 4 hasta 8 ) de la condición física del paciente y la evolución de la tumefacción (localizada o diseminada), espacios aponeuróticos comprometidos, compromiso de los tejidos blandos, condición neurológica, permeabilidad de la vía aérea y alimenticia.

10. Pasado el tiempo adecuado y determinado para que el paciente esté estable pude ser manejado con una fórmula ambulatoria.

11. Si la condición del paciente empeora es necesario hospitalizarlo.

12. Se debe monitorear al paciente con citas diarias durante la primera semana y posteriormente semanales para verificar su evolución.

13. Una vez se evidencia signos de resolución del proceso, se debe establecer las causas por las cuales se produjo el accidente, y hecho el diagnóstico se procede a reiniciar y terminar la endodoncia.

\section{BIBLIOGRAFÍA}

1. Pashley EL, Birdsong NL, Bowman K, Pashley DH. Cytotoxic effects of $\mathrm{NaOCl}$ on vital tissue. J Endodon 1985; 11: $525-528$.

2. Izu KH, Thomas S, Zhang P, Izu AE, Michalek S. Effectiveness of sodium hypochlorite in preventing inoculation of periapical tissues with contaminated patency files. J Endod 2004; 30: 82 - 84.

3. Yesilsoy C, Whitaker E, Cleveland D, Phillips E, Trope M. Antimicrobial and toxic effects of established and potential root canal irrigants. J Endod 1995; 21: 513 - 515.

4. Byström A, Sundqvist G. Bacteriological evaluation of the effect of $0.5 \%$ sodium hypochlorite in endodontic therapy. Oral Surg Oral Med Oral Pathol 1983; 55: 307 - 312.

5. Harrison JW. Irrigation of the root canal system. Dent Clin North Am 1984; 28: 797 - 808.

6. Ayhan H, Sultan N, Cirak M, Ruhi MZ, Bodur H. Antimicrobial effect of various endodontic irrigants on selected microorganisms. Int endod J 1999; 32: 99 -102.

7. Bystrom A, Sundqvist G. Bacteriologic evaluation of the effect of 0.5 percent sodium hypochlorite in endodontic therapy. Oral Surg Oral Med Oral Pathol 1983; 55: 307 312.

8. Tanomaru FM, Leonardo MR, Silva LA, Anibal FF, Faccioli LH. Inflammatory response to different endodontic irrigating solutions. Int Endod J 2002; 35: 735 - 739.

9. Gatot A, Arbelle J, Leibermann M, Yanai-Inbar I. Effects of sodium hypochlorite on soft tissues after its inadvertent injection beyond the root apex. J Endodon 1991; 17: 573 -574 .

10. Gernhardt CR, Eppendorf K, Kozlowski A, Brandt M. Toxicity of concentrated sodium hypochlorite used as an endodontic irrigant. Int Endod J 2004; 37: 272 - 280.

11. Spangberg L, Engström B, Langeland K (1973) Biologic effects of dental materials. III. Toxicity and antimicrobial effect of endodontic antiseptics in vitro. Oral Surg Oral Med Oral Pathol 1973; 36: 856 - 871.

12. Hulsmann M, Hahn W. Complications during root canal irrigation: literature review and case reports. Int Endod J 2000; 33: 186 - 193.

13. Ingram TA. Response of the human eye to accidental exposure to sodium hypochlorite. J Endodon 1990; 16: 235 $-238$.

14. Serper A, Ozbek M, Calt S. Accidental sodium hypochlorite-induced skin injury during endodontic treatment. J Endod 2004; 30: 180 - 181.

15. Yarington $\mathrm{CT}$ Jr. The experimental causticity of sodium hypochlorite in the esophagus. Ann Otol Rhinol Laryngol 1970; 79: 895 - 859.

16. Kaufman AY, Keila S. Hypersensitivity to sodium hypochlorite. J Endod 1989; 15: 224 - 226.

17. Caliskan MK, Turkun M, Alper S. Allergy to sodium hypochlorite during root canal therapy: a case report. Int Endod J 1994; 27: 163 - 167.

18. Cohen S, Burns R. Pathways of the pulp. 3er ed. St Louis: CV Mosby, 1984: 411 - 412

19. Sultzberg MB. Dermatologic allergy: an introduction in the form of a series of lectures, IL: Charles C Thomas.

20. Carson KR, Goodell GG, McClanahan SB. Comparison of the antimicrobial activity of six irrigants on primary endodontic pathogens. J Endod 2005; 31: 471-73. 
21. Dametto FR, Randi CC, Igueiredo de Almeida Gomes BP, Zaia AA, Teixeira FB, De Souza-Filho FJ. In vitro assessment of the immediate and prolonged antimicrobial action of chlorhexidine gel as an endodontic irrigant against Enterococcus faecalis. Oral Surg Oral Med Oral Pathol Oral Radiol Endod 2005; 99:768 - 772

22. Herrmann JW, Heicht RC, Complications in therapeutic use of sodium hypochlorite. J Endodon 1979; 5:160.

23. Gursoy UK Bostanci V, Kosger HH. Palatal mucosa necrosis because of accidental sodium hypochlorite injection instead of anaesthetic solution. Int Endod J 2006; 39: 157 -161 .

24. Shih M, Marshall FJ, Rosen S. The bactericidal efficiency of sodium hypochlorite as an endodontic irrigant. Oral Surg Oral Med Oral Pathol 1970; 29: 613 - 619.

25. White RR, Hays GL, Janer LR. Residual antimicrobial activities alter canal irrigation with chlorhexidine. J Endod 1977; 23: 229 - 231.

26. Versumer J, Hulssman M, Schafers F. A comparative study of canal preparation using Profile .04 and lightspeed rotary instruments. Int End J 2002; 35: 37 - 46.

27. Esposito PT, Cunningham CJ. A comparison of canal preparation with nickel-titanium and stainless steel instruments. J Endod 1995; 21: 173 - 176.

28. Oncag O, Hosgor M, Hilmioglu S, Zekioglu O, Eronat C, Burhanoglu D. Comparison of antibacterial and toxic effects of various root canal irrigants. Int Endod J 2003; 36: $423-432$.

29. Heling I, Rotstein I, Dinur T, Szwec-Levine Y, Steinberg D. Bactericidal and cytotoxic effects of sodium hypochlorite and sodium dichloroisocyanurate solutions in vitro. J Endod 2001; 27: $278-280$.

30. Lambrianidis T, Tosounidou E, Tzoanopoulou M. The effect of maintaining apical patency on periapical extrusion. J Endod 2001; 27: 696 - 698.

31. Becker GL, Cohen S, Borer R. The sequelae of accidentally injecting sodium hypochlorite beyond the root apex.Oral Surgery, Oral Medicine and Oral Pathology 1974; 38: 633 -638 .

32. Sabala CL, Powell SE. Sodium hypochlorite injection into periapical tissues. J Endodon 1989;15: 490 - 492.

33. Hauman $\mathrm{CHJ}$, Chandler NP, Tong DG. Endodontic implications of the maxillary sinus: a review. Int Endod J 2002; 35: 127 - 141

34. Ehrich DG, Brian JD, Walker WA. Sodium hypochlorite accident: inadvertent injection into the maxillary sinus. J Endodon 1993; 19:180 - 182.

35. Kavanagh CP, Taylor J. Inadvertent injection of sodium hypochlorite into the maxillary sinus. Br Dent J 1998; 185: $336-337$.

36. Reeh ES, Messer HH. Long term paresthesia following inadvertent forcing of sodium hypochlorite through perforation in maxillary incisor. Endod Dent Traumatol 1989; 5: $200-203$.

37. Becking AG. Complications in the use of sodium hypochlorite during endodontic treatment: report of three cases. Oral Surg Oral Med Oral Pathol.1991; 71: 346 - 348.

38. Mehra P, Clancy C, Wu J. Formation of a facial hematoma during endodontic therapy. J Am Dent Assoc 2000; 131: $67-71$.

39. Borden JR. Ethunandan M, Brennan, PA. Life-threatening airway obstruction secondary to hypochlorite extrusion during root canal treatment. Oral Surg Oral Med Oral Pathol Oral Radiol Endod 2006; 101: 402 - 404.

40. Witton R, Brennan PA.Severe tissue damage and neurological deficit following extravasations of sodium hypochlorite solution during routine endodontic treatment. Br Dent J 2005; 198: 749 - 750.

41. Witton R, Henthorn K, Ethunandan M, Brennan PA. Neurological complications following extrusion of sodium hypochlorite solution during root canal treatment. Int Endod J 2005; 38: 843 - 848.

42. Bhat KS. Tissue emphysema caused by hydrogen peroxide. Oral Surg Oral Med Oral Pathol 1974; 38: 304 - 307.

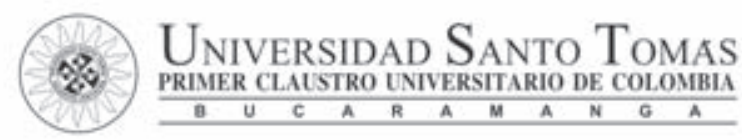

\section{Facultad de Odontología}
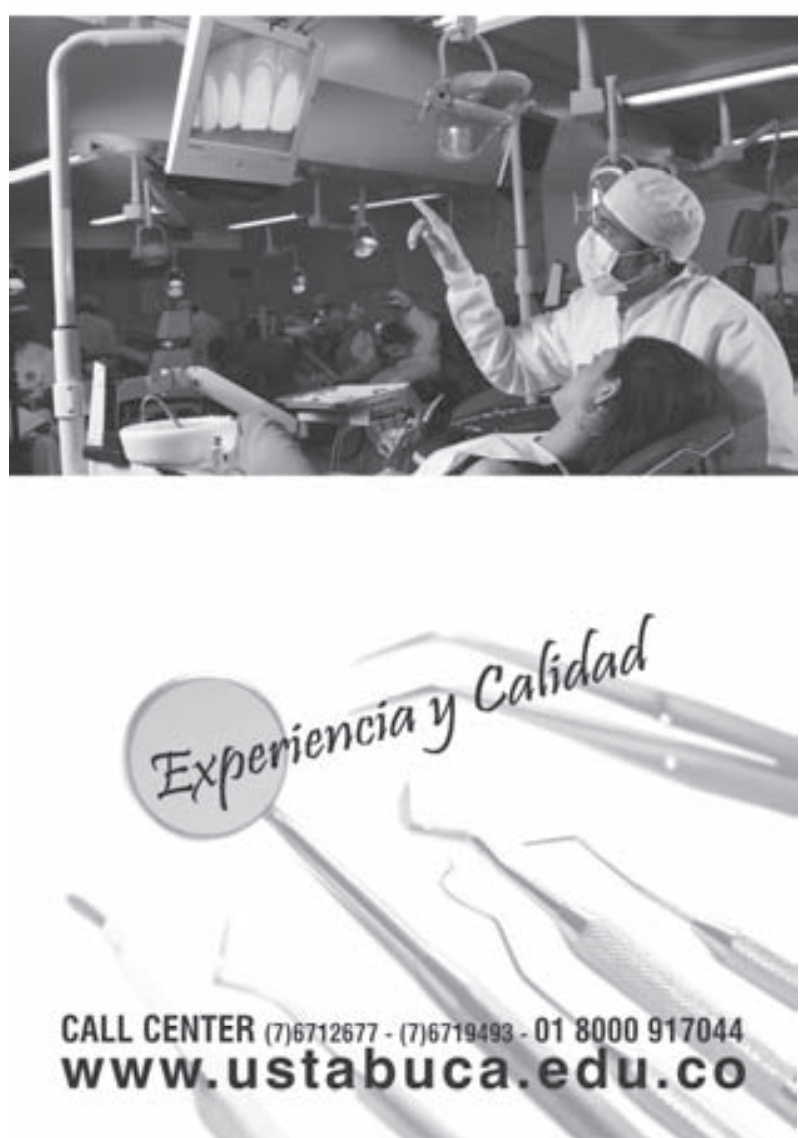